${ }^{9}$ Golden PF, Jane JA. Experimental study of irreversible shock and the brain. I Neurosurg 1973;39:434-41.

${ }^{10}$ Routh GS, Mone JG, Briggs JD, Ledingham IMcA. Survival from acute renal failure with and without multiple organ dysfunction. Postgrad Med $\mathcal{f} 1980 ; 56: 244-7$.

${ }^{11}$ Ruiz CE, Weil $\mathrm{MH}$, Carlson RW. Treatment of circulatory shock with dopamine. Studies on survival. F $A M A 1979 ; 242: 165-8$.

12 Forrester JS, Diamond G, Chaterjee K, Swan HJC. Medical therapy of acute myocardial infarction by application of hemodynamic subsets. N Engl f Med 1976;295:1356-62.

${ }^{13}$ Forrester JS, Waters DD. Hospital treatment of congestive heart failure. Management according to hemodynamic profile. Am $\mathcal{F}$ Med 1978;65: 173-80.

14 Nishijima $\mathrm{H}$, Weil $\mathrm{MH}$, Shubin $\mathrm{H}$, Cavanilles J. Hemodynamic and metabolic studies on shock associated with Gram negative bacteremia. Medicine (Baltimore) 1973;52:287-94.

${ }^{15}$ Shoemaker WC, Elwyn D, Levin H, Rosen AL. Early prediction of death and survival in postoperative patients with circulatory shock by nonparametric analysis of cardiorespiratory variables. Crit Care Med 1974; 2:317-25.

${ }^{16}$ Joly HR, Weil MH. Temperature of the great toe as an indication of the severity of shock. Circulation $1969 ; 39: 131-8$.

${ }^{17}$ Czer LSC, Shoemaker WC. Myocardial performance in critically ill patients: response to whole blood transfusion as a prognostic measure. Crit Care Med 1980;8:710-5.

${ }^{18}$ Hardaway RM. Prediction of survival or death of patients in a state of severe shock. Surg Gynecol Obstet 1981;152:200-6.

19 Griffiths J. The sequential assay of plasma catecholamines and whole blood histamine in early septic shock. In: Ledingham IMcA, McAllister T, eds. Conference on shock. London: Henry Kimpton Ltd, 1972:76-83.

20 Benedict CR, Grahame-Smith DG. Plasma noradrenaline and adrenaline concentrations and dopamine-B-hydroxylase activity in patients with shock due to septicaemia, trauma and haemorrhage. $Q \mathcal{J} \mathrm{Med} 1978 ; 47$ : 1-20.

21 Ledingham IMcA, McArdle CS, Macdonald RC. Septic shock. In: Taylor $\mathrm{S}$, ed. Recent advances in surgery. Edinburgh: Churchill Livingstone, 1980:161-99.

${ }^{22}$ Whaley K, Khong TY, McCartney AC, Ledingham IMcA. Complement activation and its control in Gram-negative endotoxic shock. $\mathcal{F}$ Clin Lab Immunol $1979 ; 2: 117-24$.

${ }^{23}$ Broder G, Weil MH. Excess lactate: an index of reversibility of shock in human patients. Science $1964 ; 143: 1457-9$.

${ }^{21}$ Perret $\mathrm{C}$, Enrico JF. Lactate in acute circulatory failure. In : Bossart $\mathrm{H}$, Perret C, eds. Lactate in acute conditions. Basle: Karger, 1979:69-82.

${ }^{25}$ Burns HJG, Cowan BN, Ledingham IMcA. Metabolic acidosis in the critically ill. In : Porter R, Alberti KGMM, eds. Metabolic acidosis. CIBA symposium 87 . (In press.)

${ }^{26}$ Schumer W. Septic shock. $\mathcal{F} A M A$ 1979;242:1906-7.

27 Shoemaker WC, Montgomery ES, Kaplan E, Elwyn DH. Physiologic patterns in surviving and nonsurviving shock patients. Use of sequential cardiorespiratory variables in defining criteria for therapeutic goals and early warning of death. Arch Surg 1973;106:630-6.

${ }^{28}$ Polanyi ML. Fiberoptics in cardiac catheterisation. I: Theoretical considerations. In: Bloomfield DA, ed. Dye curves: the theory and practice of indicator dilution. Baltimore: University Park Press, 1974:267-83.

${ }^{29}$ Kasnitz P, Druger GL, Yorra F, Simmons DH. Mixed venous oxygen tension and hyperlactaemia. Survival in severe cardiopulmonary disease. $\mathcal{F} A M A$ 1976;236:570-4

${ }^{30}$ Baker SP, C'Neill B, Haddow W, Long WB. The injury severity score: a method for describing patients with multiple injuries and evaluating emergency care. $\mathcal{F}$ Trauma 1974 ;14:187-96.

${ }^{31}$ Bull JP. The injury severity score of road traffic casualties in relation to mortality, time of death, hospital treatment time and disability. Accident, Analysis and Prevention 1975;7:249-55.

\section{The perils of abstention?}

The notion that a little of what you fancy does you good appears to receive support from a recent study by Klatsky et al ${ }^{1}$ from the Kaiser-Permanente programme. In a large 10-year prospective investigation they found that mortality varied according to the drinking habits of the individuals on entry to the study. Four groups with different levels of consumption were drawn from people undergoing multiphasic health examinations, matched according to the age, sex, and race of the highest-drinking category. The lowest mortality was found for those consuming an average of up to two drinks a day. With this rate as unity abstainers had a relative risk of 1.5 , those drinking three to five drinks daily also had a risk of $1 \cdot 5$, and $\stackrel{\text { mo }}{\frac{1}{3}}$ heavier drinkers had a risk of 2 . Plotting mortality risk against consumption thus produced a U-shaped curve. Independent $c$ confirmation of this pattern is provided by a recent London- $\widehat{\widehat{\Omega}}$ based study by Marmot et $a l,{ }^{2}$ which, though smaller in scale $\overline{\overline{5}}$ and using a different analytic procedure, also found that $\mathbb{\Phi}_{\mathbb{D}}$ moderate drinkers had a lower 10-year mortality than either $\infty$ non-drinkers or heavier drinkers. Other studies, ${ }^{3}{ }^{4}$ too, have $ᄋ$ reported a U-shaped relation. Nevertheless, if it were possible to recruit adequate samples of drinkers at higher levels of $\stackrel{5}{+}$ consumption the results would probably show not a linear but an exponential increase in mortality with increasing intake, $\frac{\bar{\sigma}}{\bar{\omega}}$ much as has been shown for cirrhosis of the liver": the " $U$ " might be a "J."

Whatever the details, it seems paradoxical that anyone's life might be shortened by the absence of a toxic substance such $\vec{\circ}$ as ethanol. The picture changes, however, when cause-specific $\overrightarrow{\vec{\omega}}$ mortality rates are considered. It then emerges from the studies $\stackrel{\circ}{\circ}$ of both Klatsky et $a l^{1}$ and Marmot et $a l^{2}$ that the excess mortality among abstainers is largely due to an increase of cardio- iv vascular deaths, the frequency of which steadily declines with $\stackrel{\infty}{\oplus}$ increasing daily consumption within the range of levels $\underset{\omega}{ }$ represented. This trend has been much explored by other $\vec{P}$ workers, with conflicting results. Conversely, other causes of $\vec{A}$ mortality-among which cancer and violent deaths figure prominently-increase with increasing daily intake, and about this relation there is general consensus in published work.

Several points need clarification before the Kaiser- $\mathbb{D}$ Permanente findings ${ }^{1}$ can be properly evaluated. Firstly, the categorisation of drinking habits is exceedingly crude with no attempt at verification, and there is no evidence that persons $\overrightarrow{\vec{\theta}}$ remained within their initial drinking category over the $10 \stackrel{\infty}{\infty}$ years of follow-up. Given that people tend to drink less as they age, ${ }^{6} 7$ the stability of drinking practices over such a period could hardly be expected. These considerations, however, would tend to blur rather than accentuate the differences among the initial subgroups. A second major query concerns $\stackrel{\odot}{\perp}$ smoking, which is relatively heaviest among drinkers. Both Klatsky et $a l^{1}$ and Marmot et $a l^{2}$ went to some lengths to $\frac{\circ}{3}$ analyse their data carefully for smoking. The Americans found the U-shaped alcohol mortality curve present at each smoking level, except, oddly enough, among those who had never smoked. Marmot et al, using a multivariate technique, again found the association between alcohol mortality to be $\frac{0}{0}$ largely independent of smoking. A third consideration is that those individuals already suffering from alcohol-related damage or suffering from any other illness at entry to the study may have given up drinking as a consequence. Klatsky et al had information at least about past heavy drinking and $N$ reanalysed their data with attention to those with and without $\rightarrow$ such a history; for both groups the same curve was obtained. In a supplementary analysis ${ }^{8}$ the London group distinguished $N$ those taking any medications or with symptoms of diabetes, $\mathbb{\omega}$ cardiovascular, or chronic respiratory disease and contrasted $\mathcal{F}$ them with the supposedly healthy remainder. Similar findings emerged for both samples, though interestingly the highest mortality of all was found in the so-called "unhealthy abstainers."

So far, then, the claim for an association between mortality and abstention holds up, but three further considerations remain. The first of these is age. Klatsky et al ${ }^{1}$ reported on a cohort whose mean age at entry was 44 , while no one below 40 was admitted to the study by Marmot et al..$^{2}$ Yet (for institutionalised alcoholics) the maximum effect of alcohol on mortality is in the first and not the second half of life. Thus in 
effect both studies were investigating a cohort of survivors. The importance of age was confirmed in the Californian work in that the relation of alcohol use to mortality was clearest among those aged under 50 and was relatively weak among those over 60 , though details were not given.

The matter of social class is at least of equal importance. Again, the Californian study identified that the light drinkers were of higher educational level than other subjects; they may therefore have had better jobs and a generally better life style. Since at least for diagnosed alcoholics social class has major effects on both total and cause-specific mortality, ${ }^{910}$ this variable must be controlled. Finally, there remains the vexed issue of the special characteristics of abstainers. Only $6 \%$ of men in England and Wales describe themselves as non-drinkers, ${ }^{6}$ and they differ from the rest of the population with respect to marital state, social class, occupational category, and where they live as well as age. In the United States the abstainer is an equally complex figure, but if the stereotype of the white, Protestant, ambitious, and upwardly striving teetotaller retains any validity it may well apply to those unusual Californian men who do not drink alcohol.

Until these uncertainties are resolved the reason for the differential mortality between abstainers and light drinkers cannot confidently be ascribed to the alcohol alone. There are certainly no grounds for exhorting non-drinkers to start tippling for the benefit of their health.

Director,

N KREITMAN

MRC Unit for Epidemiological Studies in Psychiatry,

University Department of Psychiatry,

Royal Edinburgh Hospital,

Edinburgh EH10 5HF

${ }^{1}$ Klatsky AL, Friedman GB, Siegelaub AB. Alcohol and mortality. Ann Intern Med $1981 ; 95: 139-45$.

${ }^{2}$ Marmot MG, Rose G, Shipley MJ, Thomas BJ. Alcohol and mortality: a U-shaped curve. Lancet $1981 ; \mathrm{i}: 580-3$.

${ }^{3}$ Blackwelder WC, Yano K, Rhoads GG, Kagan A, Gordon T, Palesch Y. Alcohol and mortality: the Honolulu heart study. $\mathrm{Am} \mathcal{F}$ Med 1980; 68:164-9.

4 United States Department of Health, Education, and Welfare. Second special report to the Congress on Alcohol and Health from the Secretary of Health, Education, and Welfare. Washington, DC: US Government Printing Office, 1975. (DHEW publication No (ADM)75-212.)

5 Pequignot G, Tuyns AJ, Berta JL. Ascitic cirrhosis in relation to alcohol consumption. Int $\mathcal{f}$ Epidemiol 1978;7:113-20.

6 Wilson P. Drinking in England and Wales. London: HMSO, 1980.

7 Cahalan D, Room R. Problem drinking among American men. New Brunswick: Rutgers Centre of Alcohol Studies, 1974. (Monograph No 7.)

${ }^{8}$ Marmot MG, Rose G, Shipley MJ. Alcohol mortality. Lancet 1981 ;i:1159.

${ }^{9}$ Edwards G, Kyle E, Nicholls P, Taylor C. Alcoholism and correlates of mortality. Implicators for epidemiology. F Stud Alcohol 1978;39: 1607-17.

${ }^{10}$ Nicholls P, Edwards G, Kyle E. Alcoholics admitted to four hospitals in England. II. General and case-specific mortality. Quarterly fournal of Studies on Alcohol $1974 ; 35: 841-55$.

\section{Hair-raising notions and lotions}

Attempts to provoke the pale, smooth, bald patches of alopecia areata into regrowth by making them red and angry have a natural appeal. In their turn Willan, Bateman, and Hebra all insisted that the skin had to be roused into activity and to do so used various alcoholic and ethereal fluids, some containing phenol or cantharidin, rubbed into the scalp with a stiff brush. Dermatologists persisted with these and other ways of irritating the skin but with waning enthusiasm, and in 1967 Percival $^{1}$ was able to sum up the general feeling with his sensible but negative point that "counter-irritants do not interfere with regrowth, and the patients' natural despair at a policy of inactivity is relieved by their use." The disease continued to run its own eccentric course without being influenced by the activity of the physicians. ${ }^{2}$ But now, strange as it may seem, modern knowledge about the immunology of alopecia areata has reawakened the desire to redden and anger the patches.

Alopecia areata looks most at home in the autoimmune group of disorders, but it has not yet earned full membership. Reports abound of its association with other autoimmune diseases, ${ }^{3}$ but away from the clinical context things are still less than clear cut. Antibodies to follicle antigens have not been convincingly identified, and even the deposits of $\operatorname{IgM}$ in the intercellular spaces of the external root sheaths of affected hair follicles ${ }^{4}$ have not always been found. ${ }^{5}$ In addition, circulating concentrations of $\operatorname{IgM}$ have been reported as raised, ${ }^{4}$ and as lowered, ${ }^{6}$ and there may ${ }^{7}$ or may not ${ }^{8}$ be an association with a specific HLA type. Some workers have recorded an increased prevalence of organ-specific autoantibodies in alopecia areata, particularly those directed against thyroid and parietal-cell antigens ${ }^{9}$; but this finding has not been universal. ${ }^{10}$

Of all the immunological features, the lymphocytes, looming large in alopecia areata, have most invited "stimulation." Small numbers of circulating $\mathrm{T}$ lymphocytes, ${ }^{11} 12$ an increased proportion of $\mathrm{T}$ cells with receptors for IgG, and increased antibody-dependent and cell-mediated cytotoxicity have now been reported. ${ }^{1314}$ Lymphocytes make up the bulk of the spectacular infiltrate to be seen in the early stages of the condition, hanging like swarms of bees around the hair bulbs; and their presence in the skin prompted Rosenberg ${ }^{15}$ to apply the strong contact sensitiser dinitrochlorobenzene, hoping to stimulate lymphocyte accumulation in the scalp and hence perhaps to eliminate the stimulus producing their aggregation. Skin so treated becomes suitably red and angry, as befits an allergic contact dermatitis. Other workers have since confirmed that a prolonged episode of contact dermatitis induced by dinitrochlorobenzene can often cause regrowth, ${ }^{16}$ though advancing different theories why this should be. Their reports have usually included striking photographs of patients with alopecia totalis, whose chance of spontaneous regrowth of hair must have been small, with their hair growing mainly on the treated half of the scalp. Worries about percutaneous absorption of dinitrochlorobenzene ${ }^{17}$ and its possible mutagenicity have led to the use of other powerful allergens, such as primula, ${ }^{18}$ with much the same effect.

Photographs of half-head regrowth, however, once graced descriptions of the merits of more old-fashioned remedies, ${ }^{19}$ and before any elaborate theories can be based on the specific effectiveness of an allergic type of contact dermatitis we have to know that simple irritant dermatitis of a similar intensity does not work just as well. Unfortunately, direct comparisons between dinitrochlorobenzene and dithranol, long used in alopecia areata, have been hard to interpret. If the two substances are applied to different areas of the same scalp an unusual contact allergy to dithranol may be induced. ${ }^{20}$ Dinitrochlorobenzene seems to be more effective than the irritant substance croton oil, ${ }^{21}$ but encouraging regrowth has also been produced by dithranol, applied by itself and acting only as an irritant. ${ }^{22}$

Has the wheel turned full circle? Probably not, but there are now reports of those who cannot make dinitrochlorobenzene achieve any worthwhile regrowth, ${ }^{23}$ of hair falling out again during the course of treatment, ${ }^{24}$ and of tolerance developing to dinitrochlorobenzene. ${ }^{25}$ The gaze of some may already be shifting to the early reports of other possible 